\title{
Natural History of Malignant Bone Disease in Gastric Cancer: Final Results of a Multicenter Bone Metastasis Survey
}

\author{
Nicola Silvestris ${ }^{1 *}$, Francesco Pantano ${ }^{2}$, Toni Ibrahim ${ }^{3}$, Teresa Gamucci ${ }^{4}$, Fernando De Vita ${ }^{5}$, \\ Teresa Di Palma ${ }^{6}$, Paolo Pedrazzoli ${ }^{7}$, Sandro Barni ${ }^{8}$, Antonio Bernardo ${ }^{9}$, Antonio Febbraro ${ }^{10}$, \\ Maria Antonietta Satolli ${ }^{11}$, Paola Bertocchi ${ }^{12}$, Vincenzo Catalano ${ }^{13}$, Elisa Giommoni ${ }^{14}$, \\ Alessandro Comandone ${ }^{15}$, Evaristo Maiello ${ }^{16}$, Ferdinando Riccardi ${ }^{17}$, Raimondo Ferrara ${ }^{18}$, \\ Antonio Trogu ${ }^{19}$, Rossana Berardi ${ }^{20}$, Silvana Leo ${ }^{21}$, Alessandro Bertolini ${ }^{22}$, Francesco Angelini ${ }^{23}$, \\ Saverio Cinieri ${ }^{24}$, Antonio Russo ${ }^{25}$, Salvatore Pisconti ${ }^{26}$, Anna Elisabetta Brunetti ${ }^{1}$, Amalia Azzariti ${ }^{27}$, \\ Daniele Santini ${ }^{2}$
}

1 Medical Oncology Unit, National Cancer Research Centre Istituto Tumori "Giovanni Paolo II", Bari, Italy, 2 Medical Oncology Unit, University Campus Bio-Medico, Roma, Italy, 3 Osteoncology and Rare Tumors Center, IRCCS -Romagnolo Scientific Institute for the Study and Treatment of Cancer, Meldola, Italy, 4 Medical Oncology Unit, Hospital of Frosinone, Frosinone, Italy, $\mathbf{5}$ Medical Oncology Unit, II University of Naples, Naples, Italy, $\mathbf{6}$ Medical Oncology Unit, Hospital of Latina, Latina, Italy, 7 Department of Oncology-Hematology, Hospital of Pavia, Pavia, Italy, 8 Division of Medical Oncology, Treviglio-Caravaggio Hospital, Treviglio, Italy, 9 Operative Unit of Oncology - IRCCS Fondazione Maugeri, Pavia, Italy, 10 Medical Oncology Unit, Hospital of Benevento, Benevento, Italy, 11 Department of Medical Oncology, San Giovanni Battista Hospital, Turin, Italy, 12 Department of Medical Oncology, Fondazione Poliambulanza of Brescia, Brescia, Italy, 13 Medical Oncology Unit, Hospital of Pesaro, Pesaro, Italy, 14 Medical Oncology Unit, Hospital Careggi, Florence, Italy, 15 Department of Oncology, Gradenigo Hospital and Gruppo Piemontese Sarcomi, Turin, Italy, 16 Medical Oncology Unit, Hospital "Casa Sollievo della Sofferenza”, San Giovanni Rotondo, Italy, 17 Medical Oncology Unit, Hospital "Cardarelli", Naples, Italy, 18 Medical Oncology Unit, Hospital of Barletta, Barletta, Italy, 19 Medical Oncology Unit, Hospital of Aosta, Aosta, Italy, 20 Medical Oncology Unit, University of Ancona, Ancona, Italy, 21 Medical Oncology Unit, Hospital of Lecce, Lecce, Italy, 22 Medical Oncology Unit, Hospital of Sondrio, Sondrio, Italy, 23 Medical Oncology Unit, Hospital Regina Apostolorum, Albano Laziale, Italy, 24 Medical Oncology Department \& Breast Unit - Hospital of Brindisi and Medical Oncology Department - European Institute of Oncology, Milan, Italy, 25 Medical Oncology Unit, University of Palermo, Palermo, Italy, 26 Medical Oncology Departement Hospital of Taranto, Taranto, Italy, 27 Clinical and Preclinical Pharmacology Laboratory, National Cancer Research Centre Istituto Tumori "Giovanni Paolo II", Bari, Italy

\begin{abstract}
Background: Bone metastasis represents an increasing clinical problem in advanced gastric cancer (GC) as disease-related survival improves. In literature, few data on the natural history of bone disease in GC are available.

Patients and Methods: Data on clinicopathology, skeletal outcomes, skeletal-related events (SREs), and bone-directed therapies for 208 deceased GC patients with evidence of bone metastasis were statistically analyzed.

Results: Median time to bone metastasis was 8 months ( $\mathrm{Cl} 95 \%, 6.125-9.875$ months) considering all included patients. Median number of SREs/patient was one. Less than half of the patients (31\%) experienced at least one and only 4 and $2 \%$ experienced at least two and three events, respectively. Median times to first and second SRE were 2 and 4 months, respectively. Median survival was 6 months after bone metastasis diagnosis and 3 months after first SRE. Median survival in patients who did not experience SREs was 5 months. Among patients who received zoledronic acid before the first SRE, the median time to appearance of first SRE was significantly prolonged compared to control (7 months vs 4 months for control; P: 0.0005).

Conclusions: To our knowledge, this retrospective analysis is the largest multicenter study to demonstrate that bone metastases from GC are not so rare, are commonly aggressive and result in relatively early onset of SREs in the majority of patients. Indeed, our large study, which included 90 patients treated with ZOL, showed, for the first time in literature, a significant extension of time to first SRE and increase in the median survival time after diagnosis of bone metastasis. Taken together, these data may support the beneficial effects of ZOL in GC patients.
\end{abstract}

Citation: Silvestris N, Pantano F, Ibrahim T, Gamucci T, De Vita F, et al. (2013) Natural History of Malignant Bone Disease in Gastric Cancer: Final Results of a Multicenter Bone Metastasis Survey. PLoS ONE 8(10): e74402. doi:10.1371/journal.pone.0074402

Editor: Jian-Xin Gao, Shanghai Jiao Tong University School of Medicine, China

Received February 13, 2013; Accepted August 1, 2013; Published October 28, 2013

Copyright: (c) 2013 Silvestris et al. This is an open-access article distributed under the terms of the Creative Commons Attribution License, which permits unrestricted use, distribution, and reproduction in any medium, provided the original author and source are credited.

Funding: The authors have no support or funding to report.

Competing Interests: The authors have declared that no competing interests exist.

*E-mail: n.silvestris@oncologico.bari.it 


\section{Introduction}

Gastric cancer (GC) is the fourth most common cancer diagnosis worldwide in men following lung, prostate and colorectal, and the fifth in women following breast, colorectal, cervical and lung with an expected incidence of 640,000 and 350,000 cases in 2011, respectively [1]. Approximately $8 \%$ of total cases and $10 \%$ of annual cancer deaths worldwide are attributed to GC [2]. Curative treatment of locally confined GC is gastric resection with regional lymphadenectomy intended to remove macroscopic and microscopic disease. Conversely, when distant sites are involved, no optimal therapeutic strategy has yet been established. Almost one third of GC patients presents metastatic disease and, after curative resection, over one third of all patients will eventually develop liver-specific recurrences [3]. In addition to liver spreading, other major sites of GC metastasis are peritoneum, lungs and bone. To date, only a few studies have been conducted on the onset of bone metastases in GC, with one report focused on the topic [4]. Moreover, few international guidelines recommend to routinely evaluate bone metastasis at the time of diagnosis or during follow up or pharmacological treatment. Bone metastases in GC are mainly osteolytic impairing bone integrity and inducing bone pain. Indeed, they result in significant morbidity for patients from the associated skeletal-related events (SREs), defined as pathologic fractures, the need for radiotherapy for bone pain, surgical interventions to treat or prevent an impending fracture, spinal cord and nerve root compressions, and hypercalcemia [4]. SREs cause significant decrease of functional independence, loss of autonomy and impairment of patients' quality of life [5]. Radiotherapy seems to be the most common SRE in GC patients i.e., approximately $95 \%$ of patients receive radiotherapy, $8 \%$ of them develop pathologic fractures and another $8 \%$ require surgical decompression [4]. Despite bone metastasis causes high rates of SREs, this topic in GC has received only little attention. Early detection and availability of new primary therapies have extended patient survival, thereby leaving patients with bone metastasis at risk of SREs for a longer time.

Finally this is, to our knowledge, the largest multicenter study investigating the natural history of patients with bone metastases from GC existing in literature.

\section{Patients and Methods}

\section{Ethics statement}

This multicenter retrospective observational study has been approved by the Ethics Committee of the coordinator center (National Cancer Institute of Bari). According to our Ethics Committee, a written consent was not needed. In fact, this is a retrospective observational study considering only died patients whose recruitment in the survey did not influenced their treatment.

\section{Study design}

A retrospective, observational multicenter study aimed to define the natural history of GC patients with bone metastasis was conducted in 22 Italian hospital centres in which these patients received diagnosis and treatment of disease from 1998 to 2011. Data were collected from GC patients of all ages who received standard treatments in accordance with each own treating physician's practice and were not included neither in clinical trials nor experimental protocols. Moreover, patients had at least one bone metastasis during the course of their disease and died of GC or gastric cancer-related complications. In details, patients were identified as having bone metastasis if two of the following
Table 1. Patient demographics and disease characteristics in the entire population.

\begin{tabular}{|c|c|c|}
\hline BASELINE CHARACTERISTICS & FREQUENCY & PERCENTAGE (\%) \\
\hline \multicolumn{3}{|l|}{ AGE } \\
\hline <61 YEARS (MEDIAN VALUE) & $110 / 208$ & 52,9 \\
\hline$>61$ YEARS (MEDIAN VALUE) & $98 / 208$ & 47,1 \\
\hline \multicolumn{3}{|l|}{ SEX } \\
\hline MALE & $138 / 208$ & 66,3 \\
\hline FEMALE & $70 / 208$ & 33,7 \\
\hline \multicolumn{3}{|l|}{ NODAL STATUS a } \\
\hline No & $4 / 142$ & 2,8 \\
\hline N1 & $44 / 142$ & 31,0 \\
\hline N2 & $59 / 142$ & 41,5 \\
\hline N3 & $35 / 142$ & 24,6 \\
\hline \multicolumn{3}{|l|}{ HYSTOLOGY } \\
\hline INTESTINAL & $74 / 190$ & 38,9 \\
\hline DIFFUSE & $64 / 190$ & 33,7 \\
\hline OTHER & $52 / 190$ & 27,4 \\
\hline \multicolumn{3}{|l|}{ GRADING } \\
\hline G2 & $29 / 155$ & 18,7 \\
\hline G3 & $126 / 155$ & 81,3 \\
\hline \multicolumn{3}{|l|}{ NODE DISSECTION D1 VS D2 } \\
\hline D1 & $18 / 97$ & 18,6 \\
\hline D2 & $79 / 97$ & 81,4 \\
\hline \multicolumn{3}{|l|}{ VISCERAL METASTASIS STATUS } \\
\hline NO & $28 / 204$ & 13,7 \\
\hline YES & $176 / 204$ & 86,3 \\
\hline \multicolumn{3}{|l|}{ ECOG PERFORMANCE STATUS b } \\
\hline 0 & $53 / 187$ & 28,3 \\
\hline 1 & $82 / 187$ & 43,9 \\
\hline 2 & $41 / 187$ & 21,9 \\
\hline 3 & $11 / 187$ & 5,3 \\
\hline
\end{tabular}

criteria were satisfied: physician reported bone metastasis; bone metastasis identified by bone scan; record of radiotherapy to bone as a palliative therapy; identification of bone metastasis by other imaging assessment (e.g. standard x-rays, computed tomography scans, or magnetic resonance imaging of the skeleton).

Data were collected throughout the disease course and during all cancer treatments, including surgery, radiation therapy, chemotherapy, and biological therapies. Variables assessed included age, sex, histotype, number and sites of bone metastasis, nodal stage, nodal dissection, visceral metastases, ECOG performance status at the moment of bone metastases diagnosis, time to appearance of bone metastasis, times to first and subsequent SREs (from diagnosis of bone metastasis), SRE types, survival after first SRE, and type and times of bisphosphonate therapy.

\section{Statistical analysis}

Descriptive statistics were used for patient demographics and incidence of SREs. All survival intervals were determined by the Kaplan-Meier method [6]. The differences in survival according to clinical parameters or treatment were evaluated by the log-rank 
Table 2. Patient bone disease characteristics in the entire population.

\begin{tabular}{lll}
\hline & & \\
\hline BASELINE CHARACTERISTICS & FREQUENCY & PERCENTAGE (\%) \\
\hline BONE LESION TYPE & \multicolumn{1}{l}{} \\
\hline OSTEOLYTIC & $105 / 202$ & 52,0 \\
OSTEBLASTIC & $46 / 202$ & 22,8 \\
MIXED & $51 / 202$ & 25,2 \\
BONE METASTASIS NUMBER & & \\
1 & $65 / 207$ & 31,4 \\
P1 & $142 / / 207$ & 68,6 \\
BONE METASTASIS SPINE & & \\
YES & $42 / 207$ & 20,3 \\
NO & $165 / 207$ & 79,7 \\
BONE METASTASIS LONG BONES & \\
YES & $109 / 207$ & 52,7 \\
NO & $98 / 207$ & 47,3 \\
BONE METASTASIS HIP & & \\
YES & $79 / 207$ & 38,3 \\
NO & $127 / 207$ & 61,7 \\
ZOLEDRONIC ACID TREATMENT & \\
\hline NO & $105 / 186$ & 56,5 \\
YES & $81 / 186$ & 43,5 \\
SRE TYPE (ALL) a & & \\
PATHOLOGICAL FRACTURE & $19 / 85$ & 22,4 \\
HYPERCALCEMIA & $4 / 85$ & 4,7 \\
SPINAL CORD COMPRESSION & $9 / 85$ & 10,6 \\
\hline SURGERY TO BONE & $13 / 85$ & 47,1 \\
\hline RADIATION TO BONE & $40 / 85$ & \\
\hline & & \\
\hline
\end{tabular}

ancluded first, second and third; SRE, skeletal-related event. doi:10.1371/journal.pone.0074402.t002

test and described by the Kaplan-Meier method [7] unless otherwise specified. In the univariate model, all the clinical variables were evaluated as predictors for shorter time to bone metastasis, shorter time from bone metastases to SRE and shorter time from bone metastases to death. Patients who did not have a recorded date for a specific event were censored at the date of death. Finally, the Cox proportional hazards model was applied to the multivariate survival analysis. All the significant variables in the univariate model were used to build the multivariate model of survival, and median values were derived from whole-month values rather than fractions. SPSS software (version 20.00; SPSS, Chicago, IL) was used for statistical analysis. A $P$ value $<0.05$ was considered statistically significant.

\section{Results}

\section{Patient characteristics}

The analysis of records of more than 2000 patients, died from GC, allowed to identify 208 patients $(10 \%)$ with bone metastasis. 59 of them $(28 \%)$ had bone metastasis at the GC diagnosis and $149(62 \%)$ developed bone metastasis after GC diagnosis. 137/208 patients included in this study $(66 \%)$ were male, consistent with the well-known male predominance of GC. The median age was 61 years. Tumor histology was intestinal in $38.9 \%$ of patients, diffuse in $33.7 \%$ and mixed plus undifferentiated in the remaining $27.4 \%$.

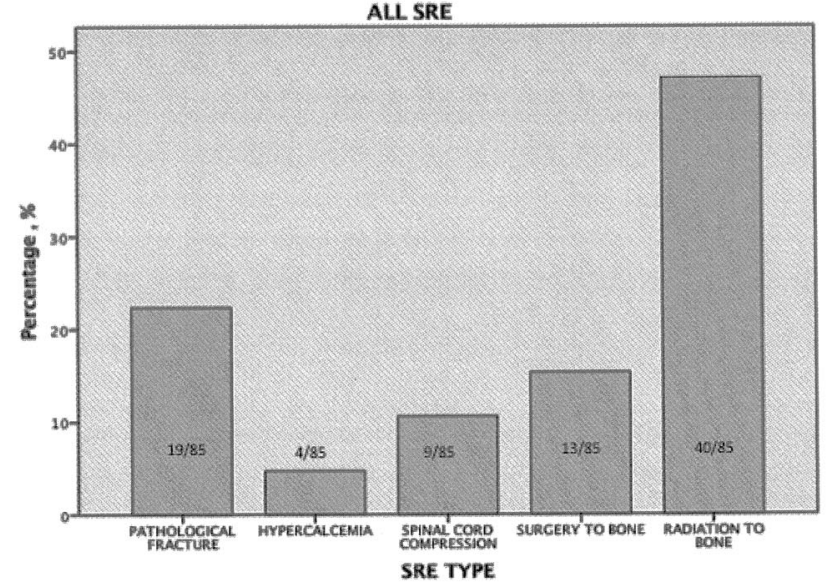

Figure 1. Percentage of skeletal-related events (SREs) occurring in patients with bone metastases from gastric cancer. doi:10.1371/journal.pone.0074402.g001

$81.4 \%$ of patients have been submitted to $\mathrm{D} 2$ node's dissection, the remaining $18.6 \%$ to $\mathrm{D} 1$ dissection. $86.3 \%$ of patients developed also visceral metastases (Table 1).

\section{Skeletal metastases}

The majority of patients $(68.6 \%)$ had multiple bone metastases and the remaining $31.4 \%$ showed single lesion. Long bones were the most common site of bone metastasis ( $52 \%$ of patients) followed by hip (38\%) and spine (only 20\% s). Osteolytic lesions $(52 \%)$ were far more prevalent in this group than the mixed ones $(25 \%)$ while osteoblastic lesions were not so rare as expected $(23 \%)$ (Table 2). Less than half of the patients (31\%) experienced at least one SRE while, two and three SREs have been reported in only $4 \%$ and $2 \%$ of patients, respectively. In Figure 1, the incidences of different SREs are reported and are consistent with previous reports i.e., radiotherapy to bone is the most common SRE $(47.1 \%$ of all events), followed by pathologic fracture (22.4\%), surgery to bone $(15.3 \%)$ and by spinal cord compression, which accounted for $10.6 \%$ of the total number of SREs experienced in this analysis. Only $4.7 \%$ of all events is represented by hypercalcemia.

\section{Predictive factors of survival after bone metastases diagnosis}

The univariate analysis, reported in Table 3, demonstrates that survival after diagnosis of bone metastases was significantly shorter in younger population (<61 years old) (p: 0.025), in patients submitted to D2 lymph nodes dissection (p: 0.009), in ECOG 2/3 patients (p: 0.002), and in patients not treated with bisphosphonates (p: 0.001). Intriguingly, in multivariate analysis (Table 4.) only D2 lymph nodes dissection independently correlates with a shorter survival after bone disease occurrence (p: 0.008; HR: 2.285).

\section{Predictive factors of onset of bone metastasis}

In univariate analysis (Table 5), the median time to the onset of skeletal disease was significantly shorter according to $\mathrm{T}$ stage $(p<0.001)$ and in patients with other than intestinal and diffuse hystology (p: 0.007), with G3 tumor (p: 0.026), and who had undergone to D2 lymph nodes dissection (p: 0.026). The multivariate analysis (Table 6) shows that only D2 lymph nodes dissection independently correlated with a shorter time to diagnosis of bone metastases (p: 0.013; HR: 2.708). 
Table 3. Median survival after bone metastases diagnosis: univariate analysis.

\begin{tabular}{|c|c|c|c|c|c|}
\hline \multicolumn{2}{|l|}{ BASELINE CHARACTERISTICS } & \multirow{3}{*}{$\begin{array}{l}\text { TIME (MONTHS) } \\
5,000\end{array}$} & \multicolumn{2}{|l|}{ 95\% C.I } & \multirow{2}{*}{${ }_{T}^{P}$} \\
\hline & & & LOWER I & T UPPER & \\
\hline \multirow[t]{2}{*}{ AGE } & <61 YEARS (MEDIAN VALUE) & & 4,165 & 5,835 & 0,025 \\
\hline & >61 YEARS (MEDIAN VALUE) & 7,000 & 5,035 & 8,965 & \\
\hline \multirow[t]{2}{*}{ SEX } & MALE & 6,000 & 4,821 & 7,179 & 0,199 \\
\hline & FEMALE & 6,000 & 3,673 & 8,327 & \\
\hline \multirow[t]{3}{*}{ HYSTOLOGY } & INTESTINAL & 7,000 & 5,656 & 8,344 & 0,136 \\
\hline & DIFFUSE & 5,000 & 4,139 & 5,861 & \\
\hline & OTHER & 5,000 & 3,766 & 6,234 & \\
\hline \multirow[t]{2}{*}{ GRADING } & G2 & 7,000 & 5,053 & 8,947 & 0,548 \\
\hline & G3 & 5,000 & 3,519 & 6,481 & \\
\hline \multirow[t]{3}{*}{ HER2 STATUS } & POSITIVE & 5,000 & 4,546 & 5,454 & 0,379 \\
\hline & NEGATIVE & 5,000 & 2,400 & 7,600 & \\
\hline & UNKNOW & 6,000 & 4,856 & 7,144 & \\
\hline \multirow[t]{2}{*}{ NODE DISSECTION D1 VS D2 } & D1 & 7,000 & 4,921 & 9,079 & 0,009 \\
\hline & D2 & 5,000 & 3,809 & 6,191 & \\
\hline \multirow[t]{2}{*}{ VISCERAL METASTASIS STATUS } & NO & 5,000 & 1,706 & 8,294 & 0,719 \\
\hline & YES & 6,000 & 5,075 & 6,925 & \\
\hline \multirow[t]{4}{*}{ ECOG PERFORMANCE STATUS } & 0 & 7,000 & 5,121 & 8,879 & 0,002 \\
\hline & 1 & 6,000 & 4,870 & 7,130 & \\
\hline & 2 & 4,000 & 2,497 & 5,503 & \\
\hline & 3 & 1,000 & NA & NA & \\
\hline \multirow[t]{3}{*}{ BONE LESION TYPE } & OSTEOLYTIC & 6,000 & 4,859 & 7,141 & 0,672 \\
\hline & OSTEBLASTIC & 6,000 & 3,110 & 8,890 & \\
\hline & MIXED & 6,000 & 4,123 & 7,877 & \\
\hline \multirow[t]{2}{*}{ BONE METASTASIS NUMBER } & 1 & 16,000 & 8,466 & 23,534 & 0,077 \\
\hline & $>1$ & 13,000 & 9,686 & 16,314 & \\
\hline \multirow[t]{2}{*}{ ZOLEDRONIC ACID TREATMENT } & NO & 5,000 & 4,147 & 5,853 & 0,001 \\
\hline & YES & 8,000 & 6,210 & 9,790 & \\
\hline \multirow[t]{6}{*}{ FIRST SRE TYPE } & NO SRE & 5,000 & 3,785 & 6,215 & 0,568 \\
\hline & PATHOLOGICAL FRACTURE & 9,000 & 2,987 & 15,013 & \\
\hline & HYPERCALCEMIA & 4,000 & NA & NA & \\
\hline & SPINAL CORD COMPRESSION & 8,000 & 0,160 & 15,840 & \\
\hline & SURGERY TO BONE & 7,000 & 5,829 & 8,171 & \\
\hline & RADIATION TO BONE & 6,000 & 3,673 & 8,327 & \\
\hline
\end{tabular}

$\mathrm{Cl}$, confidence interval; $P$ determined by Log-rank test; SRE, skeletal-related event.

doi:10.1371/journal.pone.0074402.t003

Table 4. Predictive factors of survival after bone metastases diagnosis: multivariate analysis.

\begin{tabular}{lll}
\hline & & \\
\hline BASELINE CHARACTERISTICS & $\mathbf{P}$ & HAZARD RATIO \\
\hline AGE & 0,598 & 0,888 \\
NODE DISSECTION D1 VS D2 & 0,008 & 2,285 \\
ECOG PERFORMANCE STATUS & 0,608 & 0,940 \\
ZOLEDRONIC ACID TREATMENT & 0,651 & 0,903 \\
\hline
\end{tabular}

$\mathrm{P}$ determined by Cox proportional hazards model.

doi:10.1371/journal.pone.0074402.t004
Skeletal outcomes and SREs in the overall population

All GC patients included in this study $(\mathcal{N}=208)$ showed a median overall survival time of 14 months (CI 95\%, 12.02515.975) and a median time to diagnosis of bone metastasis of 8 months (CI 95\%, 6.125-9.875 months). The median level of maximum bone pain experienced after diagnosis of bone metastasis was 8 months (range, 0-10) while, the median pain level experienced at the time of diagnosis was 5 months (range, 0 9). At the time of bone metastases diagnosis, $27 \%$ of patients showed an ECOG Performance Status of 2 or 3. The median number of SREs experienced by patients was one (range, $0-3$ ). The median time to first SRE after confirmed diagnosis of bone metastasis was 2 months (CI 95\%, 1.536-0-2.464 months), indicative of the severity of bone metastasis in GC. The median time to second SRE was 4 months (CI 95\%,3.457-4.865 months). 
Table 5. Median time to bone metastases diagnosis: univariate analysis.

\begin{tabular}{|c|c|c|c|c|c|}
\hline \multirow[t]{2}{*}{$\begin{array}{l}\text { BASELINE } \\
\text { CHARACTERISTICS }\end{array}$} & & \multirow[t]{2}{*}{ TIME (MONTHS) } & \multicolumn{2}{|c|}{ 95\% C.I } & \multirow[t]{2}{*}{$\mathbf{P}$} \\
\hline & & & $\begin{array}{l}\text { LOWER } \\
\text { LIMIT }\end{array}$ & $\begin{array}{l}\text { UPPER } \\
\text { LIMIT }\end{array}$ & \\
\hline \multirow[t]{2}{*}{ AGE } & $\begin{array}{l}<61 \text { YEARS (MEDIAN } \\
\text { VALUE) }\end{array}$ & 6,000 & 2,065 & 9,935 & 0,490 \\
\hline & $\begin{array}{l}>61 \text { YEARS (MEDIAN } \\
\text { VALUE) }\end{array}$ & 10,000 & 7,555 & 12,445 & \\
\hline \multirow[t]{2}{*}{ SEX } & MALE & 9,000 & 6,500 & 11,500 & 0,386 \\
\hline & FEMALE & 8,000 & 5,034 & 10,966 & \\
\hline \multirow[t]{4}{*}{ TUMOR STAGE } & T1 & 65,000 & 19,911 & 110,089 & $<0,001$ \\
\hline & $\mathrm{T} 2$ & 22,000 & 18,375 & 25,625 & \\
\hline & T3 & 9,000 & 5,569 & 12,431 & 12,431 \\
\hline & T4 & 6,000 & 3,143 & 8,857 & \\
\hline \multirow[t]{4}{*}{ NODAL STATUS a } & No & 65,000 & 630 & 129,370 & 0,142 \\
\hline & $\mathrm{N} 1$ & 10,000 & 6,843 & 13,157 & \\
\hline & N2 & 11,000 & 7,743 & 14,257 & \\
\hline & N3 & 12,000 & 2,758 & 21,242 & \\
\hline \multirow[t]{3}{*}{ HYSTOLOGY } & INTESTINAL & 9,000 & 6,330 & 11,670 & 0,007 \\
\hline & DIFFUSE & 10,000 & 7,425 & 12,575 & \\
\hline & OTHER & 5,000 & 1,491 & 8,509 & \\
\hline \multirow[t]{2}{*}{ GRADING } & G2 & 10,000 & 0,000 & 25,904 & 0,026 \\
\hline & G3 & 9,000 & 6,689 & 11,311 & \\
\hline \multirow[t]{2}{*}{$\begin{array}{l}\text { NODE DISSECTION } \\
\text { D1 VS D2 }\end{array}$} & D1 & 21,000 & 12,684 & 29,316 & 0,026 \\
\hline & D2 & 16,000 & 10,468 & 21,532 & \\
\hline \multirow[t]{2}{*}{$\begin{array}{l}\text { VISCERAL METASTASIS } \\
\text { STATUS }\end{array}$} & NO & 5,000 & 0,000 & 15,371 & 0,279 \\
\hline & YES & 8,000 & 6,203 & 9,797 & \\
\hline \multirow[t]{3}{*}{ BONE LESION TYPE } & OSTEOLYTIC & 8,000 & 5,681 & 10,319 & 0,257 \\
\hline & OSTEBLASTIC & 15,000 & 5,321 & 24,679 & \\
\hline & MIXED & 7,000 & 4,440 & 9,560 & \\
\hline
\end{tabular}

${ }^{\mathrm{a}}$ At time of diagnosis; $\mathrm{Cl}$, confidence interval; $P$ determined by Log-rank test; SRE, skeletal-related event.

doi:10.1371/journal.pone.0074402.t005

Table 6. Predictive factors of time of bone metastases diagnosis: multivariate analysis.

\begin{tabular}{lll}
\hline $\begin{array}{l}\text { BASELINE } \\
\text { CHARACTERISTICS }\end{array}$ & $\mathbf{P}$ & HAZARD RATIO \\
\hline AGE & 0,927 & 1,023 \\
TUMOR STAGE & 0,145 & 1,351 \\
HISTOLOGY & 0,549 & 1,110 \\
GRADING & 0,519 & 0,794 \\
$\begin{array}{l}\text { NODE METASTASIS } \\
\text { STATUS }\end{array}$ & 0,193 & 1,389 \\
$\begin{array}{l}\text { NODE DISSECTION } \\
\text { D1 VS D2 }\end{array}$ & 0,013 & 2,708 \\
\hline $\begin{array}{l}\text { determined by Cox proportional hazards model. } \\
\text { doi:10.1371/journal.pone.0074402.t006 }\end{array}$ & \\
\end{tabular}

Median survival from the diagnosis of bone metastasis was 6 months (CI 95\%,5.068-6.932 months). Median survival after development of the first SRE was 3 months (CI 95\%,2.0493.951 months). Median survival in patients who did not experience SREs was 5 months (CI 95\%, 3.785-6.125 months). All data described are reported in Table 7.

\section{Skeletal outcomes and SREs according to time of bone metastases appearance}

The entire population was divided in three subpopulations (synchronous bone metastases, metachronous bone metastases and patients with only bone metastases) and each subgroups was characterised for the following parameters: clinical, pathological and bone metastases characteristics, SREs and skeletal outcomes. Any significant difference was found in terms of age, gender, histology, visceral metastases, type, site and number of bone lesions. Intriguingly, the majority of patients $(66,7 \%)$ with only bone metastases experienced, as the more frequent SRE, radiation to bone compared with $55,6 \%$ and $52,2 \%$ of patients with synchronous and metachronous metastases, respectively. Interestingly, median survival after bone metastases diagnosis resulted the 
Table 7. Patients survival parameters according bone metastasis onset.

\begin{tabular}{|c|c|c|}
\hline PATIENTS SURVIVAL PARAMETERS & TIME, MO & 95\% C.I \\
\hline \multicolumn{3}{|l|}{ ALL PATIENTS } \\
\hline OVERALL SURVIVAL & 14 & $12,025-15,975$ \\
\hline $\begin{array}{l}\text { SURVIVAL AFTER BONE METASTASIS } \\
\text { DIAGNOSIS }\end{array}$ & 6 & $5,068-6,932$ \\
\hline $\begin{array}{l}\text { TIME TO SRE AFTER BONE METASTASIS } \\
\text { DIAGNOSIS }\end{array}$ & 2 & $1,536-2,464$ \\
\hline SURVIVAL AFTER SRE & 3 & $2,049-3,951$ \\
\hline TIME TO BONE METASTASIS & 8 & $6,125-9,875$ \\
\hline \multicolumn{3}{|l|}{ BONE METASTASIS SYNCRHONOUS } \\
\hline $\begin{array}{l}\text { SURVIVAL AFTER BONE METASTASIS } \\
\text { DIAGNOSIS }\end{array}$ & 5 & $3,461-6,539$ \\
\hline $\begin{array}{l}\text { TIME TO SRE AFTER BONE METASTASIS } \\
\text { DIAGNOSIS }\end{array}$ & 1 & $0,530-1,470$ \\
\hline SURVIVAL AFTER SRE & 4 & $3,156-4,844$ \\
\hline \multicolumn{3}{|l|}{ BONE METASTASIS METACHRONOUS } \\
\hline $\begin{array}{l}\text { SURVIVAL AFTER BONE METASTASIS } \\
\text { DIAGNOSIS }\end{array}$ & 5 & $3,830-6,170$ \\
\hline $\begin{array}{l}\text { TIME TO SRE AFTER BONE METASTASIS } \\
\text { DIAGNOSIS }\end{array}$ & 2 & $1,333-2,667$ \\
\hline SURVIVAL AFTER SRE & 3 & $2,074-3,000$ \\
\hline \multicolumn{3}{|l|}{ ONLY BONE METASTASIS } \\
\hline $\begin{array}{l}\text { SURVIVAL AFTER BONE METASTASIS } \\
\text { DIAGNOSIS }\end{array}$ & 5 & $1,679-8,321$ \\
\hline $\begin{array}{l}\text { TIME TO SRE AFTER BONE METASTASIS } \\
\text { DIAGNOSIS }\end{array}$ & 1 & $0,000-2,283$ \\
\hline SURVIVAL AFTER SRE & 3 & $1,829-4,171$ \\
\hline
\end{tabular}

same (5 months) in the three groups of patients, indicative of the poor prognosis strictly related to the presence of bone disease in GC patients. All data are summarised in Table 8.

\section{Bisphosphonate therapy}

Among the 208 patients with bone metastasis, 43.5\% were treated with zoledronic acid (ZOL) (administrated at a dose of $4 \mathrm{mg}$ every 4 weeks via 15-minute infusion, with dose adjustments based on creatinine clearance), $3.4 \%$ received pamidronate (administered at a dose of $90 \mathrm{mg}$ every 4 weeks via 2-hour infusion), and $53.1 \%$ did not receive any bisphosphonate treatment (Table 2). ZOL was generally well tolerated; only one patient developed osteonecrosis of the jaw (ONJ). Patient with ONJ underwent a computed tomography scan for confirmation; no retrospective adjudication was performed. It should be noted that no preventive dental care was offered before bisphosphonate therapy because many patients included in the study received treatment before 2006. Patients receiving ZOL treatment had a longer median survival time after diagnosis of bone metastasis compared with patients naives for treatment with bisphosphonates (8 months [CI\%, 6.210-9.790 months] versus 5 months [CI\%, 4.147-5.853 months], respectively) ( $P: 0.001$, Table 3$)$. In addition, patients who received ZOL before the onset of SRE (31 patients) have experienced it, after the diagnosis of bone metastases, in a time statistically higher than patients who did not receive treatment with bisphosphonates (7 months [CI\%,
6.790-12.430 months] versus 4 month $\quad$ [CI\%, $3.870-$ 6.600 months], P: 0.0005). (Figure 2).

\section{Discussion}

To our knowledge, this study is the largest multicenter survey investigating the natural history of metastatic bone disease in patients with GC. Bone metastasis was confirmed in approximately $10 \%$ of our screened GC patients, and this percentage is quite higher than expected [8-11]. In the present study, all patients with at least one known bone metastasis were included, conversely, several patients with poorly documented bone metastasis were omitted. Moreover, patients with documented bone metastases, but who were alive at study entry, were excluded. The high number of included patients and the restrictive inclusion criteria support the reliability of this incidence. Among the $10 \%$ of GC patients with bone metastasis, approximately one third presented it at the time of initial GC diagnosis, whereas the others developed bone metastasis during disease progression. Interestingly, median survival after bone metastases diagnosis resulted the same in both the study groups (5 months). Moreover, these two populations of bone metastatic GC patients did not shown any significant difference in terms of clinical, pathological and bone metastases characteristics, SREs and skeletal outcomes. The lack of outcome differences could be indicative of the poor prognosis linked to bone disease in GC patients. Only half of bone lesions were lytic and the blastic lesions $(23 \%)$ were not so rare as previously reported in literature $[12,13]$. The axial skeleton was involved in only $20 \%$ of GC patients included in the survey, the frequency is lower than that observed in breast cancer (83\%) [14] or reported by Park in GC (86\%) [15]. Patients showed the majority of metastatic sites in the long bones $(52 \%)$, followed by hip $(38 \%)$ and spine. However, sites of metastatic growth may be governed by the mechanism of metastasis.

Among all the clinical and pathological parameters correlated with median time to diagnosis of bone metastasis and median survival after skeletal disease appearance, only D2 lymph nodes dissection, at multivariate analysis, resulted independently correlated with both outcomes. Moreover, in univariate analysis, nodes staging did not correlate neither with time to skeletal disease, nor with survival after bone disease (data not shown). There is not a clear clinical or biological rational for explaining these correlations. It's clearly demonstrated in literature that in GC the number of examined nodes is a strong independent predictors of better survival [16-18] and, no data have been reported on a potential detrimental effect of an extensive lymphadenectomy. With the actual knowledge, we may only hypothesize on a potential cancer cell "bone spreading effect" triggered by D2 dissection. The median survival time of 6 months after diagnosis of skeletal metastasis in our study population is higher than that previously reported in literature [12]. For this reason the majority of these patients may experience extremely debilitating skeletal complications (i.e. SREs) that profoundly impact their quality of life. Median survival after SRE occurrence was only 3 months, possibly because of aggressive SREs affecting survival, or other complications related to SREs. The median time to diagnosis of bone metastasis was 8 months and the median time to first SRE was very short (only 2 months), thereby highlighting the need for effective bone-targeted therapy aiming to delay bone metastasis appearance and SREs. Bisphosphonates (such as ZOL, pamidronate, and clodronate) are highly effective inhibitors of osteoclastmediated bone resorption and have been widely used for treating and preventing SREs from bone metastases in solid tumors and multiple myeloma [18-22]. ZOL is the only bisphosphonate with 
Table 8. Skeletal outcomes and SRE according to time of bone metastases appearance.

\begin{tabular}{|c|c|c|c|c|c|c|}
\hline \multirow[t]{2}{*}{ BASELINE CHARACTHERISTICS } & \multicolumn{2}{|c|}{$\begin{array}{l}\text { BONE METASTASIS } \\
\text { SYNCRHONOUS }\end{array}$} & \multicolumn{2}{|c|}{$\begin{array}{l}\text { BONE METASTASIS } \\
\text { METACHRONOUS }\end{array}$} & \multicolumn{2}{|c|}{ ONLY BONE METASTASIS } \\
\hline & FREQUENCY & (\%) & FREQUENCY & (\%) & FREQUENCY & (\%) \\
\hline \multicolumn{7}{|l|}{ AGE } \\
\hline < 61 YEARS (MEDIAN VALUE) & $35 \backslash 59$ & 59,3 & $75 \backslash 149$ & 50,3 & $16 \backslash 28$ & 57,1 \\
\hline >61 YEARS (MEDIAN VALUE) & $24 \backslash 59$ & 40,7 & 74\149 & 49,7 & $12 \backslash 28$ & 42,9 \\
\hline \multicolumn{7}{|l|}{ SEX } \\
\hline MALE & 38159 & 64,4 & $100 \backslash 149$ & 67,1 & 22128 & 78,6 \\
\hline FEMALE & 21159 & 35,6 & $49 \backslash 149$ & 32,9 & $6 \backslash 28$ & 21,4 \\
\hline \multicolumn{7}{|l|}{ HYSTOLOGY } \\
\hline INTESTINAL & $17 \backslash 51$ & 33,3 & $57 \backslash 139$ & 41,0 & $8 \backslash 24$ & 33,3 \\
\hline DIFFUSE & $14 \backslash 51$ & 27,5 & $50 \backslash 139$ & 36,0 & $6 \backslash 24$ & 25,0 \\
\hline OTHER & $20 \backslash 51$ & 39,2 & $32 \backslash 139$ & 23,0 & $10 \backslash 24$ & 41,7 \\
\hline \multicolumn{7}{|l|}{ VISCERAL METASTASIS STATUS } \\
\hline NO & $9 \backslash 59$ & 15,3 & $19 \backslash 145$ & 13,1 & $28 \backslash 28$ & 100,0 \\
\hline YES & $50 \backslash 59$ & 84,7 & $126 \backslash 145$ & 86,9 & $0 \backslash 28$ & 0,0 \\
\hline \multicolumn{7}{|l|}{ BONE LESION TYPE } \\
\hline OSTEOLYTIC & $32 \backslash 58$ & 55,2 & $73 \backslash 144$ & 50,7 & $13 \backslash 27$ & 48,1 \\
\hline OSTEBLASTIC & $7 \backslash 58$ & 12,1 & $39 \backslash 144$ & 27,1 & $7 \backslash 27$ & 25,9 \\
\hline MIXED & $19 \backslash 58$ & 32,8 & $32 \backslash 144$ & 22,2 & $7 \backslash 27$ & 25,9 \\
\hline \multicolumn{7}{|l|}{ BONE METASTASIS NUMBER } \\
\hline 1 & $15 \backslash 59$ & 25,4 & $50 \backslash 148$ & 33,8 & 8128 & 28,6 \\
\hline$>1$ & 44159 & 74,6 & $98 \backslash 148$ & 66,2 & 20128 & 71,4 \\
\hline \multicolumn{7}{|l|}{ BONE METASTASIS SPINE } \\
\hline YES & $8 \backslash 58$ & 13,8 & $34 \backslash 149$ & 22,8 & $4 \backslash 28$ & 14,3 \\
\hline NO & $50 \backslash 58$ & 86,2 & $115 \backslash 149$ & 77,2 & $24 \backslash 28$ & 85,7 \\
\hline \multicolumn{7}{|l|}{ BONE METASTASIS LONG BONES } \\
\hline YES & $27 \backslash 58$ & 46,6 & $82 \backslash 149$ & 55,0 & $10 \backslash 28$ & 35,7 \\
\hline NO & $31 \backslash 58$ & 53,4 & $67 \backslash 149$ & 45,0 & $18 \backslash 28$ & 64,3 \\
\hline \multicolumn{7}{|l|}{ BONE METASTASIS HIP } \\
\hline YES & $19 \backslash 57$ & 33,3 & $60 \backslash 149$ & 40,3 & $11 \backslash 28$ & 39,3 \\
\hline NO & $38 \backslash 57$ & 66,7 & $89 \backslash 149$ & 59,7 & $17 \backslash 28$ & 60,7 \\
\hline \multicolumn{7}{|l|}{ BISPHOSPHONATE } \\
\hline ZOLEDRONIC ACID & $27 \backslash 59$ & 45,8 & $58 \backslash 149$ & 38,9 & $13 \backslash 28$ & 46,4 \\
\hline OTHER & $3 \backslash 59$ & 5,1 & $7 \backslash 149$ & 4.7 & $0 \backslash 28$ & 0,0 \\
\hline NO BISPHOSPHONATE & $5 \backslash 27$ & 49,2 & $84 \backslash 159$ & 56,4 & $15 \backslash 28$ & 53,6 \\
\hline \multicolumn{7}{|l|}{ FIRST SRE TYPE } \\
\hline PATHOLOGICAL FRACTURE & $2 \backslash 27$ & 18,5 & $9 \backslash 46$ & 19,6 & $1 \backslash 19$ & 11,1 \\
\hline HYPERCALCEMIA & $2 \backslash 27$ & 7,4 & $1 \backslash 46$ & 2,2 & $1 \backslash 19$ & 11,1 \\
\hline SPINAL CORD COMPRESSION & $3 \backslash 27$ & 7,4 & $4 \backslash 46$ & 8,7 & $1 \backslash 19$ & 11,1 \\
\hline SURGERY TO BONE & $5 \backslash 27$ & 11,1 & $8 \backslash 46$ & 17,4 & $0 \backslash 19$ & 0,0 \\
\hline RADIATION TO BONE & $15 \backslash 27$ & 55,6 & $24 \backslash 46$ & 52,2 & $6 \backslash 19$ & 66,7 \\
\hline
\end{tabular}

SRE, skeletal-related event.

doi:10.1371/journal.pone.0074402.t008

approved efficacy in all solid tumors. Perspective data on the efficacy of bisphosphonates in bone metastatic gastric cancer are lacking in literature. More recently, the receptor activator of nuclear factor kappa-B ligand inhibitor denosumab has also shown broad efficacy for SRE reduction in patients with bone metastasis from solid tumors [23] however, denosumab was not available outside of a clinical trial during the period spanned by our retrospective database analysis. Our large study, which included 90 patients treated with ZOL, showed, for the first time in literature, a significant extension of time to first SRE and increase in the median survival time after diagnosis of bone metastasis. Taken together, these data may support the beneficial effects of ZOL in GC patients. This findings are in accordance with recently published data showing that zoledronic acid treatment 


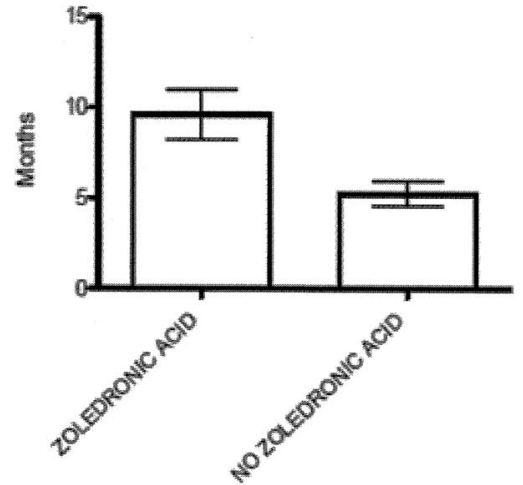

Figure 2. Comparison of time to first SRE in patients receiving zoledronic acid before SRE $(n=31)$ and those who did not receive zoledronic acid $(\mathbf{n}=\mathbf{8 5}, \mathbf{p}=\mathbf{0 . 0 0 0 5})$. Data are presented as mean \pm SEM Statistical significance was determined by Mann-Whitney test.

doi:10.1371/journal.pone.0074402.g002

significantly prolong median time to first SRE and lead as well to a trend toward an improved overall survival in bone metastatic colorectal cancer patients [24]. Additionally, although intravenous

\section{References}

1. Jemal A, Bray F, Center MM, Ferlay J, Ward E, et al. (2011) Global cancer statistics. CA Cancer J Clin 61: 69-90.

2. Guggenheim DE, Shah MA (2013) Gastric cancer epidemiology and risk factors. J Surg Oncol 107: 230-236.

3. D'Angelica M, Gonen M, Brennan MF, Turnbull AD, Bains M, et al. (2004) Patterns of initial recurrence in completely resected gastric adenocarcinoma. Ann Surg 240: 808-816.

4. Park HS, Rha SY, Kim HS, Hyung WJ, Park JS, et al. (2011) A Prognostic Model to Predict Clinical Outcome in Gastric Cancer Patients with Bone Metastasis. Oncology 80: 142-150.

5. Lipton A, Cook R, Brown J, Body JJ, Smith M, et al. (2013) Skeletal-related Events and Clinical Outcomes in Patients with Bone Metastases and Normal Levels of Osteolysis: Exploratory Analyses. Clin Oncol (R Coll Radiol) 25: 217 226.

6. Kaplan E, Meier P (1958) Non parametric estimation from incomplete observations. J Am Stat Assoc 53: 457-481.

7. Peto R, Pike MC, Armitage P, Breslow NE, Cox DR, et al. (1977) Design and analysis of randomized clinical trials requiring prolonged observation of each patient. II. analysis and examples. Br J Cancer 35: 1-39.

8. Crivellari D, Carbone A, Sigon R, Buonadonna A, Cannizzaro R, et al. (1995) Gastric cancer with bone marrow invasion at presentation: case-report and review of the literature. Tumori 81: 74-76.

9. Abrams HL, Spiro R, Goldstein N (1950) Metastases in carcinoma; analysis of 1000 autopsied cases. Cancer 3: 74-85.

10. Yoshikawa K, Kitaoka H (1983) Bone metastasis of gastric cancer. Jpn J Surg 13: $173-176$.

11. Seto M, Tonami N, Koizumi K, Sui O, Hisada K (1983) Bone metastasis in gastric cancer-clinical evaluation of bone scintigrams. Kaku Igaku 20: 795-801.

12. Park JM, Song KY, O JH, Kim WC, Choi MG, et al. (2012) Bone recurrence after curative resection of gastric cancer. Gastric Cancer 16: 362-369.

13. Nakanishi H, Araki N, Kuratsu S, Narahara H, Ishikawa O, et al. (2004) Skeletal metastasis in patients with gastric cancer. Clin Orthop Relat Res 42: 208-212.

14. Major PP, Cook RJ, Lipton A, Smith MR, Terpos E, et al. (2009) Natural history of malignant bone disease in breast cancer and the use of cumulative mean functions to measure skeletal morbidity. BMC Cancer 9: 272-284.

15. Park HS, Rha SY, Kim HS, Hyung WJ, Park JS, et al. (2011) A Prognostic Model to Predict Clinical Outcome in Gastric Cancer Patients with Bone Metastasis. Oncology 80: 142-150. bisphosphonates have been associated with dose- and infusion rate-dependent decreases in renal function [25], in the current study the renal safety profile of ZOL in GC was similar to the renal safety profile in patients not treated with bisphosphonates.

Limitations of this study include its retrospective design and inclusion of an unselected heterogeneous cohort of patients with all types of histologic variants of GC, as well as a range of anticancer therapies. However, the types of patients included in this study represent the typical scenario of a real clinical practice. Another limitation of a chart review is the heterogeneity of standardized methods used for detecting bone metastases, with each methodology having its own limit of detection.

To our knowledge, this retrospective analysis is the largest multicenter study to demonstrate that bone metastases from GC are not so rare, are commonly aggressive and result in relatively early onset of SREs in the majority of patients.

\section{Author Contributions}

Conceived and designed the experiments: NS DS. Performed the experiments: FP. Analyzed the data: FP DS NS. Contributed reagents/ materials/analysis tools: TI TG FDV TDP PP SB AF MAS PB VC EG AC EM FR RF AT RB SL AB FA SC AR SP AEB. Wrote the paper: NS DS. Helped to draft and revise the manuscript: AA.

16. Xu D, Huang Y, Geng Q Guan Y, Li Y, et al. (2012) Effect of Lymph Node Number on Survival of Patients with Lymph Node-Negative Gastric Cancer according to the 7th Edition UICC TNM System. PLoS One 7: e38681.

17. Saito H, Kuroda H, Matsunaga T, Fukuda K, Tatebe S (2010) Prognostic indicators in node-negative advanced gastric cancer patients. J Surg Oncol 101: 622-625.

18. Baiocchi GL, Tiberio GA, Minicozzi AM, Morgagni P, Marrelli D (2010) A multicentric Western analysis of prognostic factors in advanced, node-negative gastric cancer patients. Ann Surg 252: 70-73.

19. Major P, Lortholary A, Hon J, Abdi E, Mills G, et al. (2001) Zoledronic acid is superior to pamidronate in the treatment of hypercalcemia of malignancy: a pooled analysis of two randomized, controlled clinical trials. J Clin Oncol 19: 558-567.

20. Hortobagyi GN, Theriault RL, Porter L, Blayney D, Lipton A, et al. (1996) Efficacy of pamidronate in reducing skeletal complications in patients with breast cancer and lytic bone metastases. Protocol 19 Aredia Breast Cancer Study Group. N Engl J Med 335: 1785-1791.

21. Berenson JR, Lichtenstein A, Porter L, Dimopoulos MA, Bordoni R, et al. (1996) Efficacy of pamidronate in reducing skeletal events in patients with advanced multiple myeloma. Myeloma Aredia Study Group. N Engl J Med 334: 488-493.

22. Rosen LS, Gordon D, Tchekmedyian S, Yanagihara R, Hirsh V, et al. (2003) Zoledronic acid versus placebo in the treatment of skeletal metastases in patients with lung cancer and other solid tumors: a phase III, double-blind, randomized trial-the Zoledronic Acid Lung Cancer and Other Solid Tumors Study Group. J Clin Oncol 21: 3150-3157.

23. Henry DH, Costa L, Goldwasser F, Hirsh V, Hungria V, et al. (2011) Randomized, double-blind study of denosumab versus zoledronic acid in the treatment of bone metastases in patients with advanced cancer (excluding breast and prostate cancer) or multiple myeloma. J Clin Oncol 29: 1125-1132.

24. Santini D, Tampellini M, Vincenzi B, Ibrahim T, Ortega C, et al. (2012) Natural history of bone metastasis in colorectal cancer: final results of a large Italian bone metastases study. Ann Oncol 23: 2072-2077.

25. Mortimer JE, Pal SK (2010) Safety considerations for use of bone-targeted agents in patients with cancer. Semin Oncol 37 (Suppl. 1): S66-72. 